\title{
TOWARDS A SUSTAINABLE RE-CONSTRUCTION METHOD FOR SEISMIC-PRONE HERITAGE SETTLEMENTS OF GUJARAT, INDIA, BASED ON ADVANCED RECORDING TECHNOLOGIES
}

\author{
BERNADETTE DEVILAT ${ }^{1}$, JIGNA DESAI $^{2}$, ROHIT JIGYASU $^{3}$, \\ MOHAMED GAMAL ABDELMONEM ${ }^{1}$, FELIPE LANUZA ${ }^{1} \&$ MRUDULA MANE $^{2}$ \\ ${ }^{1}$ Centre for Architecture, Urbanism and Global Heritage, Nottingham Trent University, UK \\ ${ }^{2}$ Center for Heritage Conservation, CEPT Research and Development Foundation, India \\ ${ }^{3}$ International Centre for the Study of the Preservation and Restoration of Cultural Property ICCROM, Italy
}

\begin{abstract}
Post-earthquake reconstruction of housing in heritage settlements confronts challenges such as inadequate damage assessment and replacement, displaced population and loss of heritage significance. Recording the built fabric and ways of life within heritage settlements are key for conserving their historic value, which is increasingly possible with the evolution of digital technologies. This paper presents an ongoing research project developing a novel methodology for heritage conservation and post-disaster re-construction using state-of-the-art 3D-laser-scanning (LiDAR) technologies to enable comprehensive damage assessment and design of solutions for repair, retrofitting, reuse and disaster risk mitigation, facilitating community empowerment, while virtually preserving the living heritage of vernacular settlements in Kutch, Gujarat. Through the development of a scalable method of reconstruction, the aim is to break the unsustainable cycle of buildings' replacement, dereliction and subsequent loss of heritage, advancing from previous research in Chile. Key aspects of vernacular architecture in Kutch are presented alongside the critical evaluation of previous experiences of postearthquake reconstruction in the region, introducing the challenges from the LiDAR data capture done so far. The early findings show the potential of the record as fast and accurate documentation of complex living settings, incorporating the technical information required of each house within the contextual information of its surroundings - even when working remotely - where complementary social, archival and historical information can be placed and analysed.

Keywords: earthquakes, reconstruction, heritage conservation, 3D-laser-scanning, LiDAR, Kutch, India, risk mitigation, vernacular architecture, re-construction.
\end{abstract}

\section{INTRODUCTION}

Vernacular heritage is at risk of damage due to various natural and human-induced hazards everywhere in the world. However, heritage located in seismic areas faces even more challenges due to the recurrent threat earthquakes pose. Despite the periodic recurrence of earthquakes, most actions are predominantly focused on post-event response and there is little emphasis on developing proactive risk reduction measures.

The recovery of vernacular heritage is thus not often a priority after earthquakes and is usually left unattended for a long time until specific solutions are developed. This may take several years, as in the cases of the earthquakes in L'Aquila in 2009, Amandola in 2016 both in Italy; or in Zúñiga, Chile, in 2010 [1]. In India, after the Marathwada 1993 and Bhuj 2001 earthquakes, the historic villages of Killari and Adhoi, amongst many others, were abandoned, and sometimes even destroyed, and their population was relocated to new settlements that were culturally incompatible [2]. The social problems produced reveal the importance of the vernacular built environment in sustaining specific ways of living and the cultural heritage of vulnerable inhabitants. 
Regarding housing in affected areas, damaged dwellings cannot be immediately repaired and retrofitted to continue their inhabitation. Repairs are usually costly and large numbers of affected structures reduce the chances of adequate damage assessments. These conditions make the conservation of vernacular heritage difficult in the aftermath of disasters, as efforts and resources tend to focus on urgent humanitarian action. Current governmental reconstruction, with non-specific approaches, results in small new houses, sometimes relocated in a new settlement.

In response to those challenges, the project '3D for Heritage India' (https://3d4heritageindia.com) seeks to advance towards a sustainable re-construction [1] method for seismic-prone heritage settlements of Kutch, Gujarat, in the north-west of India, based on advanced recording technologies - mainly terrestrial 3D-laser-scanning (also known as LiDAR). A LiDAR record captures the physical environment in one of the most accurate, fast and comprehensive ways currently possible, resulting in a digital, measurable and coloured $3 \mathrm{D}$ point cloud with a precision of millimetres. Once the digital model of reality is obtained, it will offer a basis for damage assessments before and after a seismic event, improving the chances of a rapid and effective response, as well as offering a technical platform for risk mitigation measures. The visual outcomes of the record will also enable working with the community, increasing resilience.

The proposed methodology will take the form of a Guidance Document, applicable in similar cases, which can be adapted to different seismic areas in India, and possibly beyond. Aiming to embed it in current institutions of India, using the technology as a participatory method of engagement, a key aspect is integrating different stakeholders within the process of the research project itself: academia, local authorities, NGOs - such as the Hunnarshala Foundation - and inhabitants. Knowledge and skills transference on 3D-laser-scanning documentation for heritage structures locally is also considered, in the form of training workshops with students from the Center for Heritage Conservation (CHC) CEPT Research and Development Foundation (CRDF), as part of a complementary training project (see details in Section 6).

\section{RE-CONSTRUCTION: A VISION FOR POST-EARTHQUAKE RECOVERY IN HERITAGE VILLAGES OF CHILE}

This current study is informed by previous research on post-earthquake reconstruction in heritage villages of Chile, which are built using mainly vernacular building techniques such as adobe and quincha. Devilat [1] indicates that despite earthquakes occurring regularly, specific approaches for housing in heritage settlements are created afterwards and are insufficient to avoid large-scale damage and disruption. She proposed re-construction as an alternative vision to current reconstruction approaches mainly based on uncritical replication. By using 3D-laser-scanning for documenting the heritage settlements of San Lorenzo de Tarapacá (Fig. 1), Zúñiga and Lolol, affected by the 2005 and 2010 earthquakes, she introduced an in-depth understanding of contextual information of the whole village, recorded each in just three days. This was an experiment to see how much data could be captured in a short period, resembling a post-earthquake emergency situation, with extra days for collecting social information. Based on the resulting comprehensive and measurable 3D scanning data of what is available in each site, she proposed design strategies to increase reparation and re-use of damaged vernacular dwellings, discussed the implications of heritage reconstruction with analysis throughout different periods of time and use, and argued for the introduction of the technology institutionally. This informs a more inclusive and sustainable method for risk mitigation, re-construction and emergency actions, relevant to the case of India with similar challenges to avoid people's relocation. 


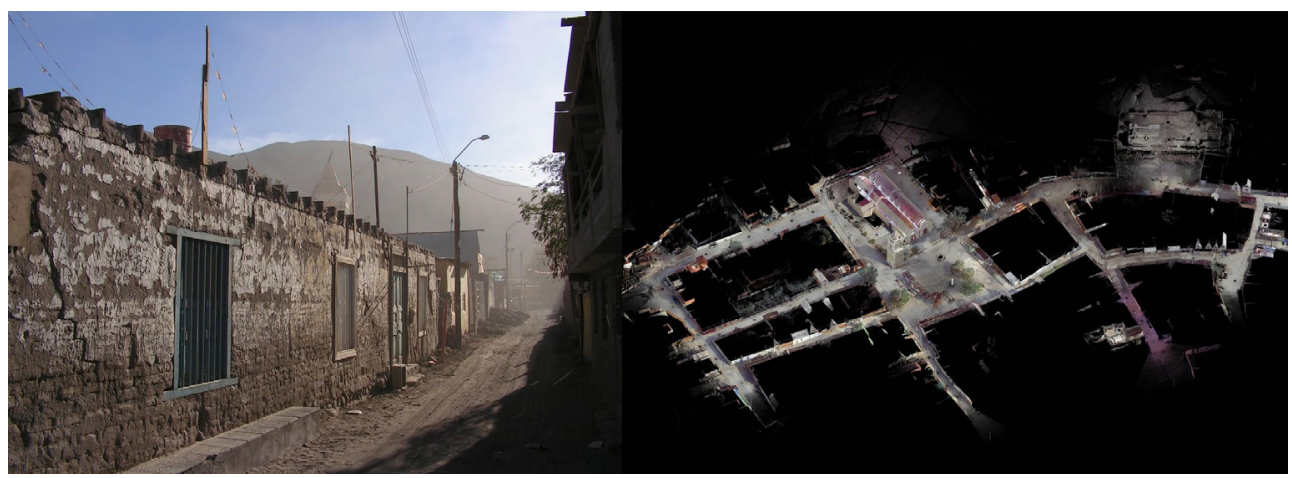

Figure 1: San Lorenzo de Tarapacá-Chile damaged after the 2005 earthquake (left) and after governmental reconstruction from the terrestrial 3D-laser-scanning obtained on-site in 2013 (right). (Source: Bernadette Devilat.)

Vernacular architecture in Chile and India is a sustainable response to their climatic conditions and cost-effective in its use of resources, with materials available locally and building techniques that have been improved from the direct observation of previous seismic behaviour. Current building techniques - with their associated social perception of status, ready-made housing provided by the State and external contractors in previous reconstruction processes, have contributed to the loss of this vernacular knowledge. This results in inhabitants not engaging in the maintenance and repair of their houses, a key aspect to secure proper seismic resistance.

Not all housing in heritage settlements can be adequately retrofitted or re-built using governmental subsidies, posing a potential danger for human life in future earthquakes, as occurred in Chile after the 2005 and 2010 earthquakes [1], and in India, after the 1993 earthquake in Maharashtra, and Bhuj 2001 [2]. Reusing and rehabilitating buildings is a sustainable mode of conservation. Constant maintenance can increase their resistance and is significantly cheaper if compared to demolishing and building anew. However, PereiraRoders and van den Brand [3] indicate that the tools available for rehabilitation lack development in comparison with those available for new constructions; a lack that also involves trying to integrate inhabitants and relevant stakeholders in the process. LiDAR technology will be employed as a tool for rehabilitation and damage assessment, providing a better basis for analysis and design. It will be a digital platform to engage with the affected community and work in the repair of their affected dwellings - when technically possible to inform new constructions based on digital data and to plan risk mitigation measures, building from its previous application in Chile.

\section{VERNACULAR HERITAGE IN KUTCH, GUJARAT}

The district of Kutch sits northwest of the State of Gujarat, west of India. It is a sort of peninsular territory extending from the Indian landmass, bordering Pakistan on the north, the Arabian Sea on the west and the Gulf of Kutch on the south. A harsh semi-arid climate predominates, and a great portion of the northern area corresponds to the Rann of Katch, which are low, flat and salty wetlands that get flooded during the monsoon season, and are mostly uninhabited. Over 900 villages are scattered across the rest of the territory, which is divided into 10 different Talukas or Tehsils. Villages corresponding to each Taluka have recognisable traits giving each their character, according to the interactions of different 
communities that have settled in the area and their own crafts, which in turn shape their layout - as is the case of Nirona [4].

The different housing typologies present across Kutch can therefore be categorised according to the communities that build them [5]. The houses of the Darbar, traditionally a martial community, are gated spaces with clearly segregated areas for men and women. Large families live in a house with a Dela (gated open space) with a shared kitchen. There is usually a semi-open Osri (a deep veranda) occupied predominantly by men. The walling material of the house could be adobe, cob or stone masonry, depending on the local resources, whilst roofs are usually timber construction with country tiles. The houses are located on high plinths to indicate the social stature of the community. Ahirs were traditionally involved in animal husbandry and their houses reflect their occupation. The houses of this community have smaller built-up areas and large open spaces to accommodate animal sheds, storage of fodder and other livelihood related activities. The houses, constructed in locally available materials, typically had a small room $(\mathrm{Ordo})$ and a kitchen. The room was a store for family valuables. This nomadic pastoral community lived in wattle and daub Bhunga (circular houses with conical thatch roof) in their native villages whilst building rudimentary tents or no shelters when migrating with their animals. Most of the Jats in this region are involved in camel herding and are not economically prosperous. This community continues to live in the traditional Pakkhas - made of reed grass, coir ropes and wood. The construction of these houses is akin to weaving and is usually done by the women of the community and can be easily moved to a different place. Their houses are usually rebuilt after every monsoon.

It must be noted that these categories are described in general terms only, as each of these communities has subcastes. Typically, a single town or a village will contain multiple community settlements, to which various artisan communities present across the region also contribute to building. They are bearers of the traditional knowledge of the region's vernacular architecture. For example, the Meghwals and the Salats are known for their stone masonry construction, Kolis specialise in thatch roofs, whereas Prajapatis were potters who also cast the terracotta roof tiles. Most of their own homes were made of wattle and daub and arranged in informal clusters on the outer edges of the villages.

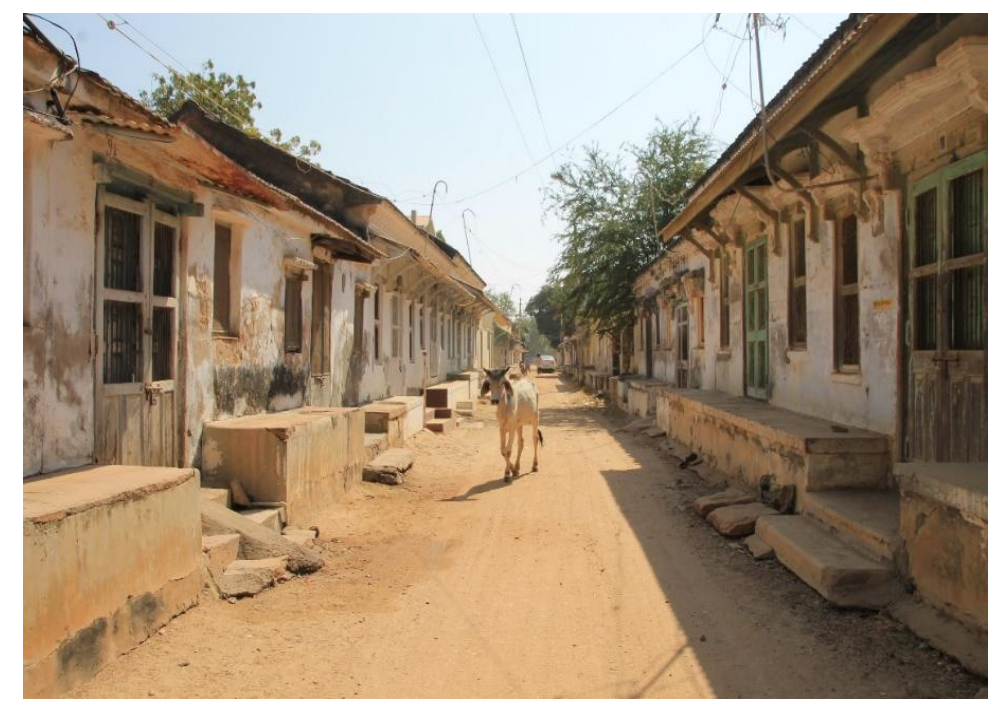

Figure 2: Moti Khakhar village in Kutch, Gujarat, India. (Source: Mrudula Mane, 2021.) 
The communities living in villages across Kutch have adapted their built environment over the years to locally available materials, the climate, as well as to their changing lifestyle. The local characteristics of vernacular architecture thus vary across the different Talukas, with each having its own character. An example of one of the recurrent traditions across Kutch, in terms of materials and construction techniques, determines that several houses are built with $50 \mathrm{~cm}$ thick stone walls and timber framing; they tend to be flat buildings with small openings, conferring resistance both to earthquakes and the hot semi-arid climate. In Moti Khakar, houses built on plinths configure a traditional streetscape (Fig. 2), resembling the continuous facades and seats that feature in villages across the desertic climate of Chile, like San Lorenzo de Tarapacá.

\section{POST-EARTHQUAKE RECONSTRUCTION EXPERIENCES IN KUTCH, GUJARAT, INDIA}

Kutch sits on a series of seven geographical faults, which makes this territory prone to earthquakes. The last great earthquake was the Bhuj earthquake, also known as Gujarat earthquake, in 2001 (7.7 Mw). Its magnitude combined with the fact that the epicentre was just $16 \mathrm{~km}$ deep produced great destruction and casualties. At least 100,000 houses were destroyed and more than 300,000 were severely damaged [6]. Many of these damaged houses, made using traditional construction techniques and representing the vernacular heritage of the region, are still lying vacant, in damaged condition, due to the post-earthquake outmigration of their population. The Bhuj earthquake triggered a huge response in terms of reconstruction of the destroyed and damaged areas. Different stakeholders were involved in each specific village coordinated by the State authority; hence a variety of reconstruction programmes took place instead of a monolithic response to the situation. Berenstein [7] groups these approaches in five distinctive categories: (1) owner-driven reconstruction with governmental assistance; (2) subsidiary housing approach, which is similar to the first but involves further assistance of an NGO; (3) participatory housing approach with an NGO assuming a leading role; (4) contractor-driven reconstruction of the affected village; and (5) contractor-driven reconstruction in the form of a new settlement or neighbourhood, apart from the affected area.

Most of the reconstruction initiatives followed the people's preference to stay in the same place instead of being relocated to a different site [8]; of which many were driven by NGOs that also worked with the local communities, actively involving them in the decision-making. The positive effects of community involvement in the reconstruction process were already acknowledged in the UNDP [6] and the World Bank [8] reports, informing reconstructions strategies. After the 1993 Marathwada and 2001 Bhuj earthquakes, the problems were the lack of technology transfer to the locals and how people returned to their original damaged settlements since 'city-like' plans for relocated villages did not consider their lifestyles [2]. The subsequent Gujarat Disaster Management Policy sought to address these problems as well [9]. Whilst these documents mention the need to train local masons to build seismically safe houses using new construction techniques, the urgency of focusing on reconstruction and rehabilitation prevented the development of an understanding of the merits of traditional construction knowledge in the region. Heritage considerations were not a part of the agenda either.

An example of a more culturally sensitive approach is the work of the Kutch Navnirman Abhiyan, a network of NGOs working in Kutch, in which the Hunnarshala Foundation takes part. Abhiyan played a key role in the reconstruction after the Bhuj earthquake, working in the villages of Reha, Bhojay and Kotdi Mahadevpuri. Their approach consisted of enabling the local people to construct their own houses and thus transfer their knowledge into the new 
structures, whilst integrating innovative solutions for water harvesting and sustainable construction. They also intended to demonstrate best practices in owner-driven housing reconstruction that could be emulated by development institutions and government authorities for larger-scale projects. In this context, Hunnarshala's particular approach to the design of new houses encompassing traditional values has been referred to as synthetic vernacular [10].

While this paper argues for a greater degree of rehabilitation of existing structures, new designs are sometimes unavoidable and play a key role in sustaining people's cultural heritage and relating to their traditional surroundings, whilst including communities' current needs and vision. Along with the importance of community engagement in the reconstruction processes in India, a significant challenge is to scale up considering the vernacular village as a whole, each house in relation to others around it and to its context, and to increase coverage to diminish relocation and dereliction. The LiDAR record offers the capability to map the existing built fabric comprehensively and accurately, to enable integral approaches that can tackle these challenges, following Desai's [11] understanding of heritage conservation essentially as an inclusive and participatory practice towards long-term sustainable development of the affected communities.

\section{RECONNAISSANCE TRIP: THE CURRENT SITUATION}

A reconnaissance trip across the district of Kutch was done to evaluate the state of different villages affected by the Bhuj earthquake, informing the selection of a case study for the LiDAR survey. The local team visited twelve villages in four days, located in the northeast, south and west areas of the district: Bela, Vrajvani, Moti Reha, Nani Reha, Nani Tumbdi, Depa, Moti Khakkar, Bhojay, Kotdi Mahadevpuri, Roha, Tera, and Jadva. The selection of villages visited responds to previous knowledge of the region in the research team (in both academic and professional capacity), and a preliminary trip by Aditya Singh from Hunnarshala, to look across a diversity of places with a significant presence of traditional architecture at risk and greater potential of collaboration with local people.

After 20 years, the memories of the 2001 earthquake are still strong. Villagers recall how traditional houses resisted the quake, although resulting in different levels of damage. The region has a strong culture of social work and community participation, key factors for effective recovery after disasters such as earthquakes. Therefore, the traditional houses that were repaired and regularly maintained since then, are still standing today. Whilst some areas recovered to different degrees, the destruction produced by the earthquake forced individuals and communities to migrate, with the negative associated social changes that result from the abandonment of many neighbourhoods and in some cases even entire villages. People considered that a collaborative initiative of 3D-laser-scanning the traditional constructions in the area can be significant in supporting their post-disaster response and appreciate the opportunity of being involved in this research project.

The villages visited feature diverse aspects of vernacular heritage worth recording for purposes of studying traditional construction systems and conservation, although not counting with legal recognition and protection. The selection criteria are summarised in Table 1. Important considerations were the potential official heritage recognition of the village considering its immediate vicinity to an already recognised heritage asset, and the existence of previous records to better understand the changes and persistence of the built fabric over the years. 


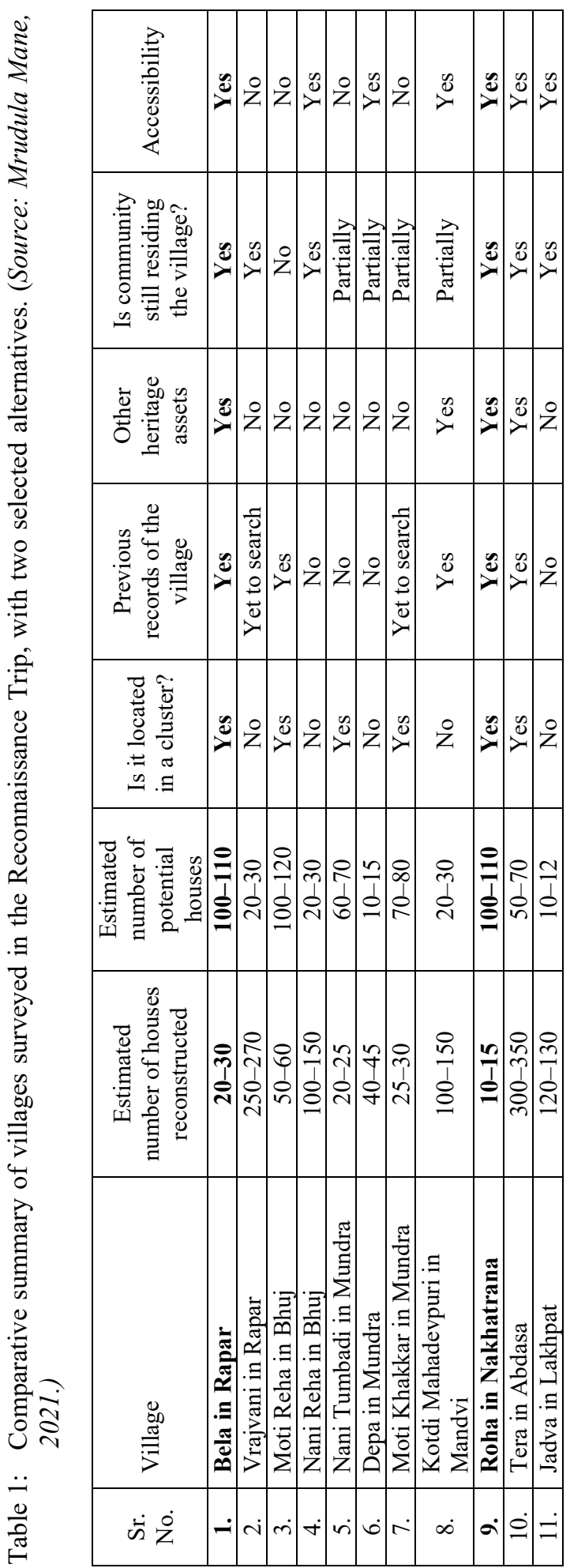


The project will focus on Bela (Figs 3-5), situated in the northeast of Kutch between its major fault lines. Bela is characterised by a coherent built fabric of continuous facades and porticoes. Most houses were damaged by the 2001 earthquake but did not completely collapse. Bela's traditional constructions conforming the area to scan are arranged around a Darbargadh or small fortification, placed in the centre of the village. There are approximately 30 abandoned residential units within the fortification, surrounded by several inhabited houses.

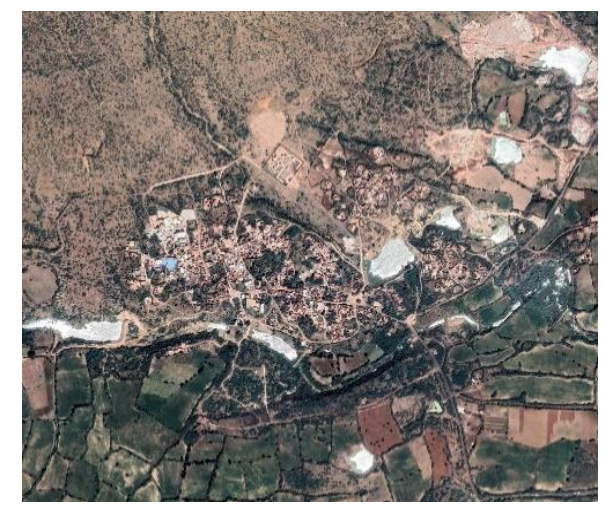

Figure 3: Aerial Photograph of Bela in Kutch, Gujarat, India, May 2020. (Source: Google Earth.)

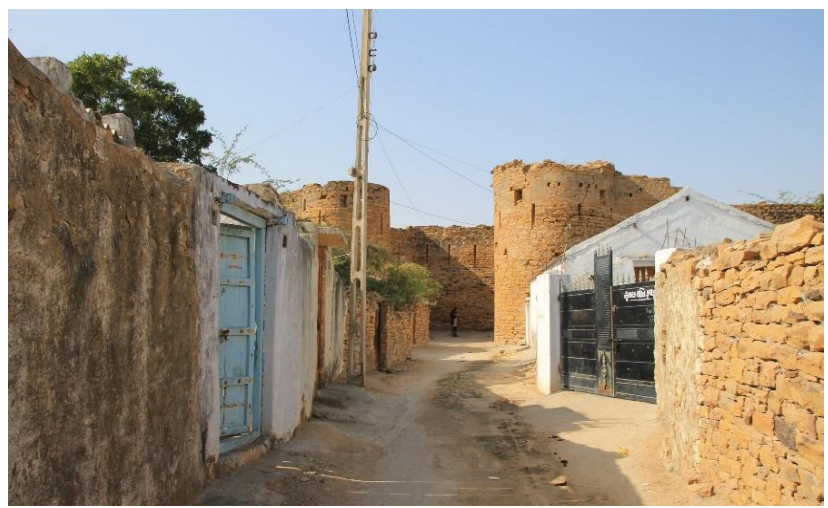

Figure 4: Bela village in Rapar, Kutch, Gujarat, India. (Source: Mrudula Mane, 2021.)

Bela's location responds well to practical aspects of the LiDAR data capture as a training workshop for students and staff at CEPT University, as well as other stakeholders in the context of the related training project (see next section). Its officially recognised heritage asset, the Darbargadh, sits within the village and not outside of it - as is the case of Roha, facilitating the overall data capture. Bela has a cohesive and numerous resident community to follow on to the next stage of community engagement using the captured data, which means that more people may benefit directly from the LiDAR record in terms of assessment compared to other potential case studies. 


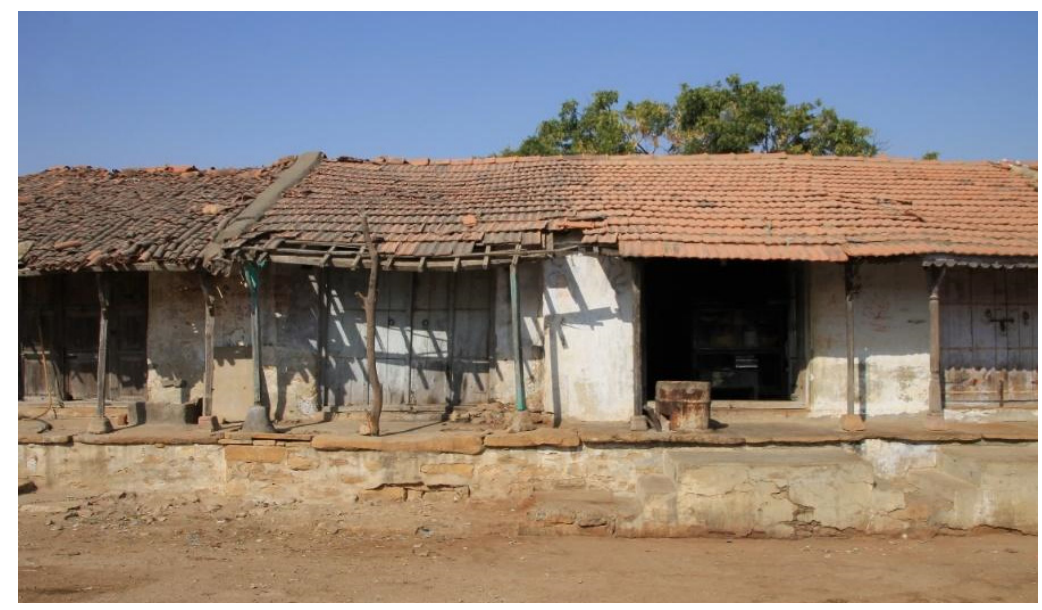

Figure 5: Bela village in Rapar, Kutch, Gujarat, India. (Source: Mrudula Mane, 2021.)

\section{LIDAR SURVEY OF HOUSES IN AHMEDABAD: SHAPING OUR WAY FORWARD}

Much of the effort in digital technologies for heritage conservation over the past two decades had primarily been directed towards accurate documentation, recording and representation of historic sites and buildings with not much emphasis on the socio-spatial patterns of human aspects of city life [12], [13]. The proliferation of the use of 3D modelling techniques, nonintrusive imaging, geophysics and augmented reality cameras has offered a multiplicity of platforms to simply store, archive and communicate vast amounts of information on cultural heritage sites, traditions and contents [14]. Whilst current advanced recording technologies offer unprecedented capabilities for documenting and visualising heritage, the innovation of this project is not in the technology itself but in its application for developing a scalable re-construction method. For this, the survey of Bela using LiDAR technologies and questionnaires to local people, and the further analysis relating archival and historical information, constitutes a pilot case study for similar settlements.

For the technical aspects of LiDAR documentation, it is relevant to embed the skill in the new generation of conservation professionals, which has been done through a parallel training project titled: 'Surveying heritage buildings in Ahmedabad, India: empowering local action and skills for heritage conservation' (https://ntu3dscanlibrary.com/). This project aims to generate local capacities for recording, surveying and protecting vernacular heritage buildings, as a knowledge transfer to improve their maintenance and tackle deterioration, by giving access to a Faro $\mathrm{m} 70$ 3D scanner and providing training to tutors who will then transfer the skills to students. One of the activities of this project consisted of a LiDAR workshop of two residential buildings in Ahmedabad. This workshop included an introductory session to explore the uses of this technology in the conservation of heritage buildings and planning the on-site scanning using previous records; on-site capturing sessions over two days; and a remote final session on post-processing, combining the scans, visualising and discussing the results. Each day on-site, one building was scanned by the leading tutor Mrudula Mane and seven students, following a similar training scheme tested before in London, UK [15].

The Ahmedabad Municipal Corporation has identified and listed 2,236 residential structures situated within the World Heritage Site of the walled city as heritage assets. The 
two houses documented (Figs 6 and 7) are listed heritage buildings of Grade III status. The scanned buildings are situated in the densely populated traditional neighbourhood known as Zaveri Wad in Kalupur ward, custodied by the religious organisation Jinagya Awas Trust.
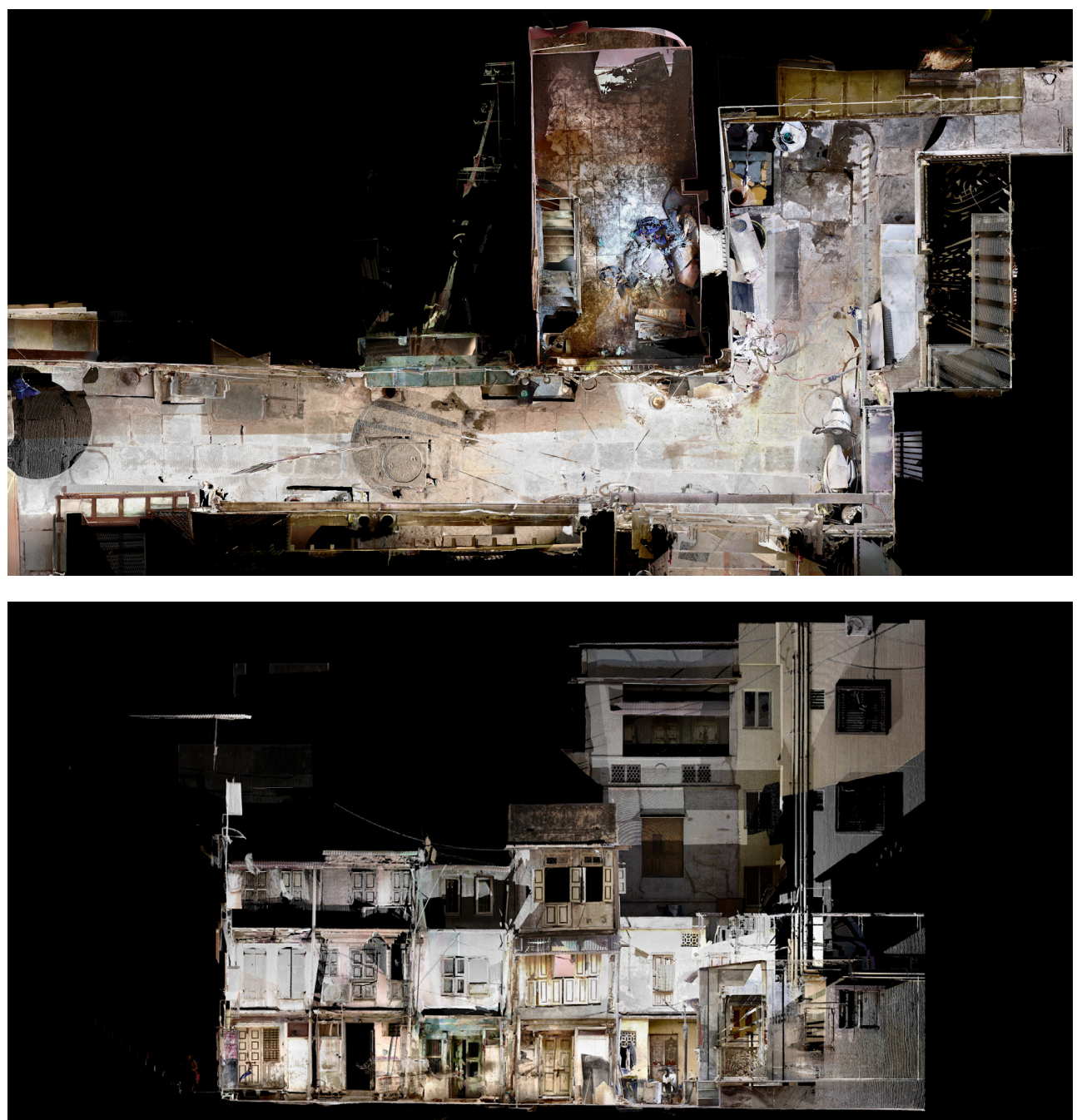

Figure 6: Ground floor plan and elevation of house 361, Ahmedabad. (Source: Bernadette Devilat, 2021, using 13 3D scans captured by Mrudula Mane and workshop participants, see acknowledgements.)

The narrow houses $(2.5 \mathrm{~m}$ to $4 \mathrm{~m})$ have steep wooden staircases, presenting an intricate and challenging setting for a LiDAR survey. Nonetheless, the scans were successfully combined into a three-dimensional model with less than $5 \mathrm{~mm}$ of maximum error in only a couple of hours. The data captured shows the buildings' context in rich detail, which corroborates the potential of this tool to understand vernacular heritage within a wider scope. 

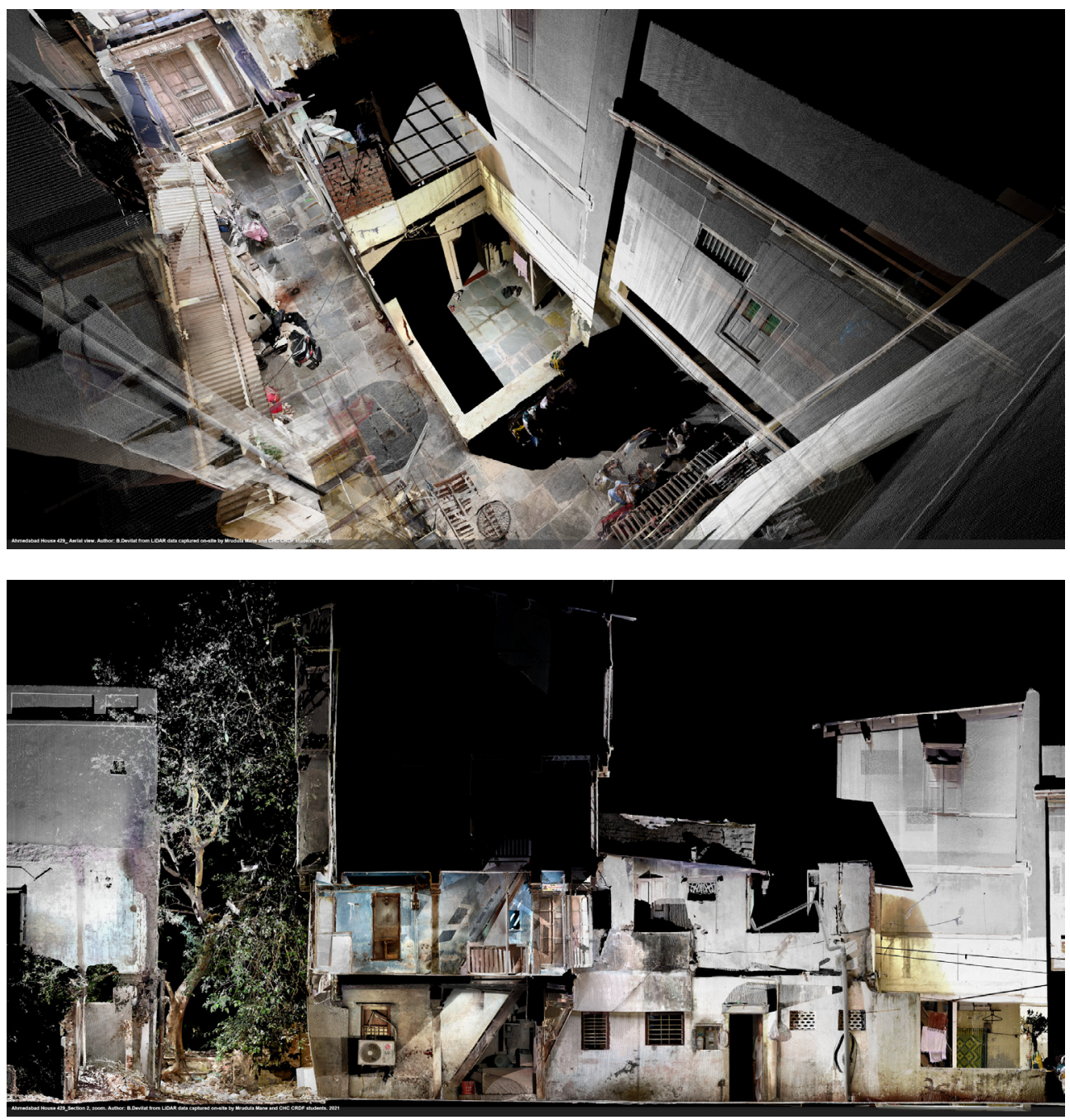

Figure 7: Aerial view and section of house 429, Ahmedabad. (Source: Bernadette Devilat, 2021, using $113 D$ scans by Mrudula Mane and workshop participants, see acknowledgements.)

It will offer better visualisation - images, videos and architectural drawings - to provide technical assessments and be used as unprecedented and accurate information of the context to develop risk mitigation and re-construction strategies considering the re-use, rehabilitation and repair of existing constructions.

\section{CONCLUSIONS AND PROJECTIONS}

Documenting buildings, especially those with historic value, is more than just capturing the physical condition of their structure. It is about recording the history of a place and the life around it. The LiDAR documentation process, as demonstrated through the Ahmedabad 
example, records the complexity of the place as found in a short period, which can be of extreme relevance for documentation after disaster and conflicts by offering a platform for action research. This record also has the potential of bringing out the nuanced differences in the way members of a community live and how they practice their culture. If studied carefully, it can potentially suggest which human associations with the built environment are enduring and which are temporal, besides the technical information about building systems, earthquake damage, distortions and use.

The associated training scheme not only served as a knowledge transfer experience but facilitated working remotely, based on what was captured on-site by the local team, which is relevant in the context of restrictions posed by the COVID-19 pandemic and opens new forms of site-specific working in challenging contexts.

The re-construction method under development in this project goes beyond the documentation. The record allows for the in-depth study of material culture and ways of living of the domestic typologies presented, but only if used as a combination of sources such as social, archival and historical information. Following that, it is expected to use the LiDAR record as a mapping basis to analyse, measure and visualise the vernacular housing elements identified in this paper with occupancy and insights provided by its inhabitants, construction systems and traditional techniques that withstood the earthquake, among other aspects. In this way, it will contribute to enhancing the number and quality of heritage buildings conserved, reducing risks to these buildings and human lives. As a potential tool for improving public policies, it could also enable a more culturally sensitive approach to the conservation of vernacular heritage, particularly to its re-construction after earthquakes as an alternative to the complete replacement of buildings.

\section{ACKNOWLEDGEMENTS}

This project is funded by the UKRI Arts and Humanities Research Council (AHRC) and the Department for Digital, Culture, Media and Sport (DCMS). Project Reference: AH/V00638X/1. With thanks to Faro Technologies for their support and Jinagya Awas Trust in Ahmedabad for facilitating access to the buildings captured during the LiDAR training workshop. Thanks to the participating students: Anushka Mital, Kanchi Chaudhari, Neha Chandel, Satyajeet Chavan, Anagha L., Bhanumati V., Sneha Anand, and the Teaching Assistants Juhi Bafna and Zeus Pithawala. With thanks also to Aditya Singh from Hunnarshala Foundation, our Project Partner, for his constant support and proactive participation. Thanks to Sandeep Virmani and Mahavir Acharya, also from Hunnarshala. During the reconnaissance trip across Kutch and the data capture in Ahmedabad, members of this project carefully observed COVID-19-related preventive measures to protect staff students and surrounding communities and will continue to do so in the following fieldwork and engagement activities. The training project "Surveying heritage buildings in Ahmedabad, India: empowering local action and skills for heritage conservation", which is complementary to 3D for Heritage India, is funded by Nottingham Trent University.

\section{REFERENCES}

[1] Devilat, B., Re-construction and record: Exploring alternatives for heritage areas after earthquakes in Chile. PhD thesis, The Bartlett School of Architecture, University College London, 2018.

[2] Jigyasu, R., From Marathwada to Gujarat - Emerging challenges in post-earthquake rehabilitation for sustainable eco-development in South Asia. First International Conference on Post-disaster Reconstruction: Improving Post-Disaster Reconstruction in Developing Countries, Montreal, pp. 1-22, 2002. 
[3] Pereira-Roders, A.R. \& van den Brand, G.J.W., Sustaining rehabilitation: A call to strengthen the building rehabilitation knowledge base. Proceedings of the CIB W70 Trondheim International Symposium: "Changing User Demands on Buildings - Needs for lifecycle planning and management", Trondheim, pp. 128-138, 2006.

[4] Desai, J., Conservation of a craft habitat; mapping spatial and temporal networks of the crafts practices of Nirona, Kutch. Doctoral thesis, CEPT University, 2014.

[5] Hunnarshala Foundation, People in centre, Buildaur, \& thumb impressions. Socio Technical Facilitation of IAY in Gujarat: Housing Typology Study, Commissionerate of Rural Development, pp. 32-40, 2014.

[6] From Relief to Recovery: The Gujarat Experience, United Nations Development Programme (UNDP), p. 9, 2001. https://www.in.undp.org/content/india/en/home/ library/environment_energy/from-relief-to-Recovery.html. Accessed on: 7 Apr. 2018.

[7] Berenstein, J.D., Housing reconstruction in post-earthquake Gujarat. A comparative analysis, The Humanitarian Practice Network at the Overseas Development Institute, London, 2006.

[8] Gujarat Earthquake Recovery Program Assessment Report, World Bank and the Asian Development Bank, p. 3, 2001. https://reliefweb.int/sites/reliefweb.int/files/ resources/788AADD8C64A0D16C1256A1C00461C35-worldbank-indannexes14mar.pdf. Accessed on: 7 Apr. 2018.

[9] Gujarat State Disaster Management Authority, Gujarat earthquake reconstruction and rehabilitation policy. 2001.

[10] Gillick, A., Synthetic vernacular - The coproduction of architecture. PhD thesis, University of Manchester, 2013.

[11] Desai, J., Equity in Heritage Conservation, the Case of Ahmedabad, Routledge: Oxon and New York, 2019.

[12] Yang, C., Peng, D. \& Sun, S., Creating a virtual activity for the intangible culture heritage. 16th International Conference on Artificial Reality and TelexistenceWorkshops, ICAT'06, pp. 636-641, 2006.

[13] Goodrick, G. \& Gillings, M., Constructs, Simulations and Hyperreal Worlds: The Role of Virtual Reality (VR) in Archaeological Research, eds G. Lock \& K. Brown, On the Theory and Practice of Archaeological Computing: Oxford, pp. 41-58, 2000.

[14] Abdelmonem, M.G., Virtual Heritage: Global Perspectives for Creative Modes of Heritage Visualisation, Nottingham Trent University: Nottingham, 2017.

[15] Devilat, B., '3D laser scanning built heritage: St. Boniface's Church as a teaching experience. Proceedings of Digital Cultural Heritage: FUTURE VISIONS London Symposium, Brisbane, pp. 18-38, 2019. 